\title{
Our Relationship with the Image as a Form of Being-With
}

\author{
Kenneth Feinstein \\ Sunway University \\ Centre for Research-Creation in Digital Media \\ No. 5, Jalan Universiti \\ 47500 Bandar Sunway Selangor Darul Ehsan \\ Kuala Lumpur, Malaysia \\ kenf@sunway.edu.my
}

\begin{abstract}
This paper looks at the development of the artistic work from a narrative work into an experiential one. How the presentation of sublime in art has moved us away from finding meaning in narrative into taking on meaning through facing our relationship to the other. It traces how this change in communication has meant that the viewer's experience with a work is the work. It takes an historical and theoretical perspective before discussing a proposed project, The Lamps of Presence, as a work employing these theories.
\end{abstract}

Media art. Media archaeology. The sublime. Expanded media. Post-modern theory.

\section{INTRODUCTION}

In this paper we will look at the work The Lamps of Presence. In order to understand this work, we have first look at the theoretical and art historical context, which it developed from. Later we will look at the work itself as an object that embodies these concepts and presents them to the viewer. This work is present as a way of understanding an important function of the technical image exploiting it so that it comes to the fore.

As image making has developed from the Renaissance through to the contemporary the relationship between the image and content has likewise evolved and changed. The art historical narrative since Giorgio Vasari's The Lives of the Most Excellent Painters, Sculptors, and Architects, has been on the myth of the genius and the singular vision brought forward to a public. In the 19th century we saw a schism between the avantgarde and the modern in which the avant-garde moved away from the beautiful image into the psyche and politics. By contrast, Modernism became interested in form itself questioning the nature of perception and the form of painting. These directions tended towards a focus on understanding the visual as something that could be read and debated as opposed to looking at art as an experience. This has. This presented the artist as having the task of presenting a vision to a viewing public. This vision is part technical, the development of innovations from horizon line perspective to cubism, and part moral, from religious painting to the sublime. The artist as genius was one who combined both what is perceived as a new vision and the sublime in an idiosyncratic or personal style.

In the late $18^{\text {th }}$ and early $19^{\text {th }}$ centuries a few developments in philosophy converged with technology to create a new way of seeing and approaching the world. Photography although presented to the pubic in 1839 , began its significant development in late $18^{\text {th }}$ century with Thomas Wedgewood and Humphry Davy (Batchen 1997). More than a technical development photography is created within the intellectual milieu in which Kantian rationalism and Romanticism are developing. Wedgewood and Davy were steeped not only in juncture of industrial and scientific development, but also in philosophical changes too. As Geoffrey Batchen points out, during their unsuccessful attempts at developing photography Wedgewood and Davy shared their work with Coleridge, who was not only a Romantic poet, but an early advocate of Kant in the UK. In these intellectual circles the newly developed ideas of the sublime were known. Edmund Burke's $A$ Philosophical Enquiry into the Origin of Our Ideas of the Sublime and Beautiful (Burke 1986) would be familiar with all three and through Coleridge, Kant's work on the sublime in the Critique of Judgment (Kant and Walker 2007). 
Burke and Kant changed the idea of the sublime from simply a rhetorical trope or an aesthetic judgement into a transcendental experience. Significantly, Kant distinguishes between beauty and the sublime. As Jacques Rancière points out for Kant, "the beautiful is that which pleases without a concept" (Rancière 2013). While the sublime is a transcendental experience, it is both supplemental to the work of art and it is where a transcendental meaning is found. Or to use the language of Roland Barthes, beauty is in the realm of stadium and the sublime in the punctum (Barthes 1981). At that time, high art was still seen to have the function of depicting the religious, political and moral, all ideas of a programmed or socially agreed upon view of the world. Diderot saw the scene in a painting as creating a tableau vivant, the moment where the whole of the story is found (Barthes and Heath 1977). We find this from Renaissance painting to the development Modernist art. The artists function became to present a moral lesson in the form of the narrative while also possessing an individual style that distinguishes this painting from all others. By contrast, the sublime brings in the idea of a viewer's personal experience. It is understood that the work may present the sublime to me, yet it may not do so to you. The sublime is understood as a personal experience. From this change from classical to modern art comes the movement from the moral narrative to the experiential in imagery.

\section{MEDIA AS EXPERIENTIAL DEVICES}

Running as a counter narrative to the tableau vivant structure in Western culture was the development of experiential devices. Best known of these early such works are those found in the Museo Kircherianum at the College of Rome. These works are attributed to Athanasius Kircher, who's Ars Magna Lucis et Umbrae and Musurgia Universalis Sive Ars Magna Consoni et Dissoni are our primary remaining records of these devices. Here early sound devices, installations and projections were created (Zielinski 2006). As the College of Rome was established an educational institution by the Jesuits, the nature of the works found in the museum were intended to reinforce what would be considered a proper Catholic education. These early works were of a large scale and can be seen as the beginning of installation art. Still narrative in function, they presented their ideas through an experiential presentation. The dislocation found in a viewer being confronted for the first time with disembodied sounds or projected images created a feeling akin to that which Deleuze refers to as an event. In this type of work this dislocation is intended to make one contemplate our place in the physical and metaphysical world. For us, the distinguishing characteristics are that they change one's relationship to the image, we are no longer disembodied viewers looking upon a scene unrelated to us. And that this experience becomes one of our establishing relationships with this work. We are not gazing upon a work that is disconnected and distant from us, we are involved in a becoming, a changing and evolving experience, which can only occur through our relationship with this object as being other than us. What is presented to the viewer is a relationship of self, as viewer, to the work as other that highlights each defines the each other.

As much as we feel that our identity is defined by consciousness, we are also defined by our relationship to the Other. Our place in the world is created by how we interact with the world. We are formed by that which is other than us as much as we are defined by an individual consciousness. Being-with is about how we relate to and are connected with the world as other than ourselves. This relationship, being-with, to the object makes presence the defining aspect of our relationship to otherness. It gives us an awareness of our connection to the other that physically places in the world.

Between this early work by Kircher and modern media art is a large gap where the two distinguishing aspects mentioned above were separated and fused back together. This is where media archaeology has developed its focus on experience in art and its delivery systems.

If we look at the Enlightenment and Modern worlds, we can see art being focused on moral/political narratives and Romanticism focusing on the sublime. They seem to be two opposite poles of one world view. Yet at the same time there a form of popular entertainment that used both the narrative/ historical aspects of Neoclassical art and the sublime as found in Romanticism combining it into one form. This was the panorama.

The panorama and later the diorama were developed as a unique form based on creating an immersive experience for a large audience. The images were in a large circular room with a scene painted as a single continuous image. Because the image took up the whole of the viewer's field of vision, it created a feeling of prescience different from theatre. The images were an extended landscape depicting remote sites, such as Alpine scenes that are related to the early writings on the sublime, religious scenes, Jerusalem and the crucifixion, and historical events. As the development of the panorama in 1787 was contemporaneous to the rise and fall of Napoleon it is only natural that many of his battles were depicted (Oettermann 1997). Panoramas, moving panoramas and dioramas all took the Neoclassical 
paintings idea of the tableaux vivant and transformed it into an experience. The viewer is presented with a view that is what its inventor Robert Barker called a "picture without boundaries". The image transforms the horizon line framed painting where the viewer gazes upon a window view of another world into one where the viewer is placed in relation to this horizon. The relationship of the horizon to the viewer is one that places the viewer in relation to what is seen. A feeling of being in the in the same space as what is being seen is established. The image viewed is much like what one would see it they were on the top of a mountain or the roof of a cathedral viewing the landscape around one. The idea is to allow the audience to have an overview of what is seen while still feeling like they are part of the event seen. It is a space designed specifically to create a sense of presence. The immersive nature of the scale and the later theatrical elements developed in the diorama are meant to create a dramatic effect where separation of the viewer from the image breaks down; giving us our first immersive experience. It becomes the template that we find in VR today. This immersive experience is meant to be a collective one as panoramas and dioramas were housed in large purpose built structures. Where the theatrical experience at this time was found in proscenium theatres in which the action occurs on an elevated framed space resembling a painting (the tableaux vivant), the view in the panorama was at eye level and some larger ones were complete spheres in which the view walked through the space creating a narrative effect. As we move into the immersive frameless space, we experience what is before as actual. The created experience is incorporated into lived experience. We feel placed within the event and we take it on as we do the world around us. As much as we can look at panoramas and dioramas as a technology superseded by later technologies, we need to understand that it brought forward the idea of the importance of presence in the work and that it is still a model for media practises today.

With the development of photography, the modern media device was invented. The relationship between image maker and medium changes as well as the relationship between image maker and the subject of the image. As the image was now documentary in that what is seen, the subject, had to be in front of the device for the image to be made. There is a factuality to the image that is new.

Along with this the nature of the between image maker and subject becomes more equal. As anyone with a camera can be a photographer, amateur photography is born. The image maker does not have to be a specially trained person given a special societal status. The one being photographed can become the photographer at any moment. Where one could draw a person from memory, but one cannot photograph them from memory. An image is made by being in that place at that time. As a device based on time and place the camera became the first device of being-within-the-world. It can only function in a moment of being-with the other. It brings self and other into relationship through the very act of creating the image. Through the device they enter into a more mutual relationship. As an artefact of such a moment the image created places the viewer into a relationship with the event of photography. If we see this as part of the nature of the camera, then we can understand that whether the images produced are moving or reduced to digital code is not relevant, as this nature of the moment of photograph doesn't change.

Just as cinema replaced the panorama, so did it take over in the worlds of art and journalism. Starting with the early $20^{\text {th }}$ century avant-garde, the photographic image as collage, photography, documentary and cinema became part of how we understood and experienced the world. Movements such as Dadaism and Surrealism exacerbated the divide between the beautiful and the sublime, rejecting the former to enhance the experience of the latter. They saw beauty as a mask from reality, one that they were happy to tear off. It was only by having the image confront us with a truth hidden from us, that we can really face the world. Given this where is the camera's place in this process? Rosalind Krauss saw the use of photography as the need to bring the indexical into art. This is a way of grounding art into the real (Krauss 1977) making it more meaningful. Parallel to this and found in the work of the same artists was the desire to create experiential works. Where still images captured a moment in time, Happenings and installations are about the viewer's presence/ participation being crucial to the existence of the piece. By being participatory these works move away from the traditional narrative process into one were meaning is derived from the viewer's own actions. Artists became interested in moving images and the nature of viewing as an experience.

Nam June Paik's Zen for Film (Fluxfilm \#1) is just a reel of clear film, yet what happens in this work that it both highlights the very idea of cinema as pure projection, a flickering light reflected on a wall. As it is played it takes on a history of its own (Uroskie 2014). With each projection of the film it gets scratches and picks up bits of dirt. These artefacts become visible on the screen, they become the image. Because the there is no image in the conventional sense, viewers so not need to focus on whatever is before them on the screen. They are more likely to be aware of the projector as a light source, to look at the cinema as a space and the projection as a unique event. At the same time, 
what is on the screen is a history of past events by way of the "damage" to the film stock. These scratches become a trace of the other that has gone before us. This work is a precursor to Derek Jarman's Blue where the entire film is made up of a single hue of blue. It is accompanied by an essayistic narrative about many things, but primarily Jarman's going blind from AIDS. Here the scratches on the film are meant to become analogous to the floating objects we see in our own eyes. As the film becomes more "damaged" we are made to feel that we are experiencing what Jarman is seeing. We experience his situation as our own. In this way he is demanding that we take responsibility for the other.

The History of Another and Writing on the Wall both by Shimon Attie are works were photographic images are projected on to urban environments, Rome for History and Berlin for Writing. They present us with an absence, the disappearance of these communities, through the images of these people projected into the spaces where they used to live and work. The impact is not found in the narrative of an erased people, but rather in an experience of being-with these people; having to face them even if only as images in this specific space. This is what creates meaning. As Emmanuel Lévinas says our responsibility to otherness is found in that face before us. We live our responsibility to the other through our being in relation to them as a physical presence (Lévinas 1998). He emphasises that our responsibility to the other is what defines us as individuals. It comes before self and self comes from it. But most importantly this responsibility is one that we experience in our lives; it is something that we live. The ethical is found when we look another person in the eyes and see our humanity in them. This is what Attie's work does to us.

\section{THE LAMPS OF PRESENCE}

Continuing with the ideas of making works that create a relationship with otherness through a sense of presence, the work The Lamps of Presence has been conceived and is being developed. While the title makes reference to John Ruskin's The Seven Lamps of Architecture, this work is not intended to be an extension of his philosophy. Rather the title is to acknowledge a continuity of the importance of physical space as a vehicle for meaning through experience.

The work is a series of glass lamps hung from the ceiling in which the light source is replaced with a small projector. Instead of projecting light out to illuminate a room, these lamps project a video image back onto the walls of the lamp. See figure 1. Each lamp is to be installed in a different location. So that for example, one lamp will be in Kuala Lumpur and another in Helsinki and a third in Boulder, Colorado. Along with the lamp a camera in the same location, will be streaming an image of a panoramic view of that city. The lamp will display an image streamed from one location to the other. While the camera is the source of the images for a different location. This would mean that the image from Kuala Lumpur would be transmitted to Helsinki, the Helsinki image to Boulder and that one back to Kuala Lumpur, thus connecting each location to the other in a network.

As we can see in Figure 1, the projector is placed on the top of the glass body of the lamp. It projects down to a circular into a mirrored disc, which reflects the image back on to the circular wall of the lamp where the image is seen by the viewer. The electronics for streaming, a micro-computer is installed above at the ceiling level. What the viewer sees is moving images streaming around the body of the projector. They experience the object as both an everyday object in their environment and as a device that presents an image of otherness back to them, creating an uncanny effect.

As viewers of media, we are used to seeing remote images in our life without even thinking about it. But these images are normally framed by a computer monitor, television or even a tablet or phone. We normally experience images within the confines of the frame. The framed image is a device used to remove the viewer from the scene viewed. Referred to as the Window Metaphor, it allows the viewer to have a distance from the scene viewed. This distance is intended to allow a separation, which gives the viewer the ability to make judgement on the scene. The framed image is a central part of the narrative image.

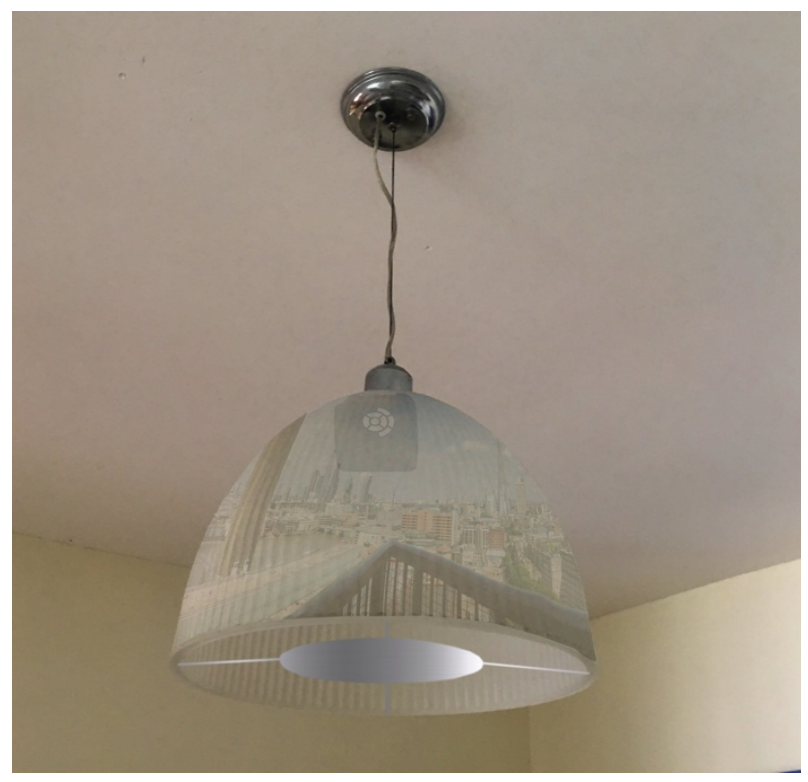

Figure 1: Artist's rendition of The Lamps of Presence 
For the viewer of The Lamps of Presence, the uncanny aspect of this work is present because it breaks away from the window and places the image into our lived world. It contains a different type of physicality that is not found in the framed image. It is this fusing of the physical and the disembodied nature of the projected image, which captures the attention of the viewer. The viewer goes through a process of first understanding the lamp is not a normal source of light, but a source of imagery. This is followed by recognising that the image is a) live and b) from a remote location. This raises questions of location (ours and the image's) as well as our relationship to time and place. The image is live, because of this it could be a night scene; a live scene of "last night" that is happening now. As we experience different parts of the world at once, we are living within different times at once.

From Kant's sublime to Alain Badiou's Event, the sense of being out of time is recognised as a defining experience. What distinguishes the event is that it is an occurrence, it happens in time. When we are confronted with an event it is disruptive. Our experience of it is as a thing out of joint with normal life. Where we normally think of life as a series of logical and understandable moments linked in time, events are experienced as ruptures of this logic. We normally live in a world where daily is governed by memory, our knowledge of what will happen from past experience (Bergson 1988). As we live in a world with where the past-present guide is through life safely and assuredly, the event ruptures this. We most notably think of disasters as events because their experience causes this break with normal life and time (Deleuze and Parnet 1987). As a sublime experience, art too can be an event. In its function as sublime it is assumed to present a metaphysical truth beyond what is readily visible to us in the world; the meaning behind what we see. As with the disaster as event, the sublime presents us with an unsettling feeling of something beyond our control

In essence we are creating an event in the form of a device. The device brings remote events into our presence in a way that is not centred on a detached remote viewing. Even if one in the room is not paying attention to the image, if they are going about their normal lives, they are still interacting with in a way that is more akin to being in a room with another person. The image has a physicality and is continuous; it can't be turned off, to see it is to engage with the image, while to ignore it one still has to be aware or its presence. Since it is both helping to illuminate the room and cannot be altered by the viewer one confronts it as another, with all the good and bad connotations that implies. It is meant to bring a consciousness of otherness to the viewer as they experience a connection to a remote sight outside of the comfort of the framed image. We can say that by making us aware of time it is also taking us out of time as a normal lived experience. The uncanny nature of reacting to several time frames at once reminds us of how we experience the present and its fragility. As an event it reminds us that what we experience is always connected to other experiences. The connectedness of the work serves to remind us that as individuals we are only in relation to the others that are prior to us and those that will follow; the viewer of a distant place becomes a face of another that brings humanity to them and us.

A further variation of the work being discussed it to have multiple lamps with a range of sources both live and recorded present in the same space. Here it would be hoped that the engagement between the images and the viewer would bring the idea of people and images in dialog more to the fore. Where the first installation design is based on the idea that the object part of a normal lived space where normal life is transformed through this intervention of this uncanny device. This full room installation would exist within the idea of the art space as event. A space that by entering into we conscious leave the world and make room mentally, emotionally and physically to be in something that is other than our lives. This brings the work into more of the Modernist paradigm of work of art as a sublime event. As we develop this work and experiment with various forms of presentation, we will see how this project will develop, always trying to find ways to make the work create the most profound experience of being related to otherness.

\section{REFERENCES}

Barthes, R. (1981) Camera lucida: reflections on photography, New York: Hill and Wang.

Barthes, R and Heath, S. (1977) Image, music, text, New York: Noonday Press.

Batchen, G. (1997) Burning with desire: the conception of photography, Cambridge, MA; London: MIT Press.

Bergson, H. (1988) Matter and memory, New York: Zone Books.

Burke, E. (1986) A philosophical enquiry into the origin of our ideas of the sublime and beautiful, Notre Dame: University of Notre Dame Press.

Deleuze, G. and Parnet, C. (1987) Dialogues, New York: Columbia University Press.

Kant, I. and Walker, N. (2007) Critique of judgement, Oxford; New York: Oxford University Press.

Krauss, R. (1977) Notes on the Index: Seventies Art in America. October 3: 68-81. 
Lévinas, E. (1998) Entre nous: on thinking-of-theother, New York: Columbia University Press.

Oettermann, S. (1997) The panorama: history of a mass medium, New York: Zone Books.

Rancière, J. (2013) Aisthesis: scenes from the aesthetic regime of art, London; New York: Verso Books.
Uroskie, A. V. (2014) Between the black box and the white cube: expanded cinema and postwar art, Chicago; London: University of Chicago Press.

Zielinski, S. (2006) Deep time of the media: toward an archaeology of hearing and seeing by technical means, Cambridge, MA: MIT Press. 